\title{
ScIDic
}

International Journal of Veterinary Health Science \& Research (IJVHSR)

ISSN: 2332-2748

\section{Review On Antibiotics Residue In Beef: Its Risk Factors and Public Health Impacts}

Abriham Kebede ${ }^{1 *}$, Mati Roba ${ }^{2}$

${ }^{1}$ School of Veterinary Medicine Wollega University, P.O.Box, 395, Nekemte, Ethiopia.

${ }^{2}$ College of Agriculture and Veterinary Medicine, Addis Ababa University, Ethiopia.

\section{Abstract}

Veterinary drugs are critically needed to meet the challenges of inadequate supply of food for the growing world population; however, the benefits of drug administration to farm animals are also accompanied by the risks associated with drug residues in the edible parts of treated animals. Nearly $50 \%$ of the globally produced antibiotics are used as growth promoters in animals. Antibiotic residues in food of animal origin remain a topical issue throughout the world. The major causes of drug residue accumulation in food-producing animals include improper withdrawal periods, failure to maintain treatment records, overdose, or using prohibited drugs for animal treatment. Humans acquire the risk by ingestion of beef that has antimicrobial residue levels higher than the maximum residue limit and the acceptable daily intake. The antibiotic residue is one of the hazards that have a bad effect on humans and animals. In Africa, the agricultural sector consumes a large portion (50\%) of antibiotics in animal farming which are used to treat ailments, minimize potential outbreaks of diseases, or promote animal health. A literaturebased review was made to assess the source of antibiotic residue in beef, to investigate its risk factors and public health significance as well as to highlight the main control measures against antibiotic residue problem in beef cattle and humans. There is no clear regulation to control antibiotic contamination of feedstuffs. Effective prevention of infectious diseases, adoption of strict hygiene standards, and using plant-derived antimicrobial substances and probiotics are some of the preventive measures.

Keywords: Antibiotic; Antibiotic Residue; Beef; Public Health; Risk Factors.

Abreviations: AMR: Antimicrobial Resistance; DNA: Deoxyribonucleic Acid; EEC: Council Regulation; ELISA: EnzymeLinked Immunosorbent Assay; ELU: Extra-Label Drug Use; EU: European Union; HPLC: High Pressure Liquid Chromatography; IgE: Immunoglobulin E; MRL: Maximum Residue Limit; MRLs: Maximum Residue Limits; NAT: Nouws Antibiotic Test; OTC: Oxytetracyclin; RNA: Ribonucleic Acid; TLC: Thin-Layer Chromatography; UV: Ultra Violet; VMPs: Veterinary Medicinal Products; WHO: World Health Organization.

\section{Introduction}

A major public health issue is foodborne diseases caused by biotoxins, microbial and chemical contaminants. Microbiological, chemical, and physical risks are the main group of risks to food safety in the food industry [52]. Veterinary drug or veterinary medicinal products (VMPs) are urgently required to meet the challenges of supplying sufficient quantities of food for the world population as drugs boost weight gain rates, improve food efficiency [23], or prevent and treat disease in food-producing animals [8].

Antibiotics are one of the most important medical discoveries [9] either naturally produced by living organisms or synthetically generated in the laboratory, and they can destroy or prevent the growth of microorganisms [43]. Owing to the extensive use of the molecules, for preventive and curative therapeutic purposes and as food additives or growth promoters, Antibiotic residues in food of animal origin remain a topical concern worldwide [7]. Antibiotic residue occupies a prominent position among the chemical contaminants present in foods [48]. The most widely used antimicrobials in food-producing animals are $\beta$-lactams, tetracyclines, aminoglycosides, lincosamides, macrolides, pleuromutilins, quinolones, chloramphenicol, and sulphonamides [1].

Globally, it is estimated that $50 \%$ of the world antibiotics are used as growth promoters in animals [5]. However, the benefits of drug administration to farm animals are also accompanied by the

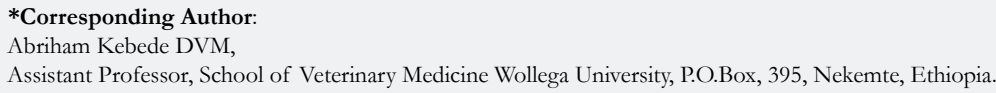

Citation: Abriham Kebede, Mati Roba. Review On Antibiotics Residue In Beef: Its Risk Factors and Public Health Impacts. Int J Vet Health Sci Res. 2021;9(1):260-265. doi: http:// dx.doi.org/10.19070/2332-2748-2000049

Copyright: Abriham Kebede DVM ${ }^{\circ} 2020$. This is an open-access article distributed under the terms of the Creative Commons Attribution License, which permits unrestricted use, distribution and reproduction in any medium, provided the original author and source are credited. 
risks associated with drug residues in the edible parts of treated animals. Antibiotic administration in food-producing animals needs consideration not only of effects on the animal but also of the effects on humans who consume food from such animals [2]. The major causes of accumulation of drug residue in food-producing animals include insufficient monitoring of withdrawal periods, failure to keep treatment, overdose, or the use of banned antibiotics for economic animal care [1].

Human acquires the risk by ingesting antimicrobial residue [17] in beef which has residue level that surpasses the permissible residue limits and reasonable daily intake [36]. The excessive use of such antibiotics in animal production had led to their accumulation in animal tissues such as muscles, heart, liver, kidney, at levels above the relative maximum residue levels (MRLs) [3].

Residue from antibiotics is one of the threats that harm the bodies of humans and animals. Improper administration by farmers and veterinarians of antimicrobials without following the withdrawal time leads to the evolution of antimicrobial resistance (AMR) in pathogens, in both humans and animals [7]. These problems include toxic effects, transfer to humans of antibiotic-resistant Bacteria [6], immunopathological effects, carcinogenicity (e.g., sulfamethazine, oxytetracycline, and furazolidone), the toxicity of bone marrow (chloramphenicol), estrogenic, neurotoxicological effects, teratogenicity, and allergy [49].

Prolonged exposure to subtherapeutic antibiotic doses results in the development of resistant bacterial strains (18), which may pass AMR genes to other bacteria organisms, with difficulty predicting the human health effect [47]. There are various screening techniques for the detection of antibiotics in beef, such as enzyme-linked immunosorbent assay (ELISA), thin-layer chromatography (TLC), commercial ampoule test, and Nouws antibiotic test (NAT). However, some researchers combine the immunoaffinity column, HPLC, and liquid chromatography for specificity and result confirmation (44). Microbial agar diffusion tests have been widely used for the detection of antibiotic residues in foods from animal origin [49].

Concern about the use of antimicrobial products in food-producing animals in recent has centered on human food safety because foods of animal origin are vectors of foodborne disease in peoples [41]. To safeguard human health, the EU (European Union) has defined, at the community level, safe maximum residue levels (MRLs) for veterinary medicinal products in foodstuffs of animal origin under council Regulation 2377/90 EEC and its later modifications [32].

Some preventive measures include the successful prevention of infectious diseases, the implementation of strict hygiene guidelines, and the use of plant-derived antimicrobials and probiotics [44]. Agricultural sectors in Africa use a significant proportion $(50 \%)$ of antibiotics in animal farming to prevent or to mitigate possible disease outbreaks or to encourage animal health [1].

There is however no specific policy in developing country to monitor feed contamination with antibiotics and to control the use of antibiotics in cattle farming. Also, there is a lack of knowledge available on antibiotic residue in animal-derived foods, many farmers treat their animals without knowing the conditions and quantities to administer or the withdrawal times and there is not as much community understanding that addressed the various effects it causes in developing countries in humans [7].

\section{Objectives}

To review the available documents and examine risk factors of antibiotic residues in beef, address the public health consequence, and highlight suggested control strategies.

\section{Antibiotic Residues}

Antibiotics are substances either produced naturally by living organisms or produced synthetically in the laboratory and they can kill or inhibit the growth of other microorganisms [54]. Residual amounts of antibiotics or their toxic metabolites found in meat, organs, or other products such as milk and egg of food-producing animals are called antibiotic residues [53]. A residue results when a drug or pesticide is deliberately applied to a food-producing animal or plant. Residues of veterinary drugs include the parent compounds and/or their metabolites in any edible portion of the animal product and include residues of associated impurities of the veterinary drug concerned. In developing countries, the risk of antibiotic residue is higher due to a lack of detection facilities and regulatory bodies that monitor the drug residues level in foods in the form of maximum residue limits (MRLs) [7].

\section{Antibiotic residues in beef}

Antibiotics are very effective and are commonly used for therapeutic purposes as a veterinary medicine as well as for prophylaxis and growth promotion [27]. DNA topoisomerases, protein synthesis, cell division and growth, and/or cell wall synthesis of disease-causing or infectious microorganisms are inhibited by these substances. Roughly $80 \%$ of food animals are currently receiving antibiotics for part or most of their lives which can contribute to residual accumulation in animal products [45]. several types of antibiotics are commonly administered to animals that provide food, including Tetracyclines, Sulfonamides, Fluoroquinolones, Macrolides, Lincosamides, Aminoglycosides, Beta-lactams, Cephalosporins, and others. Oxytetracyclinesare the most predominantly prescribed antibiotics in Africa, and they represent $41 \%$ of cases, followed by $\beta$-lactams at $18 \%[15]$.

\section{Origin of antibiotic Residues}

Antibiotics typically use in farm animals for therapeutic and prophylactic functions which can be administered in the feed or the drinking water.

The majority of residues found in edible tissues of animals are provided at the farm of origin. In some cases, the residues might proceed from contaminated animal feedstuff [35].

\section{Risk Factors for The Development of Antibiotics Residue in beef}

Antibiotic residues in food of animal origin remain a topical issue throughout the world because of the massive use of these molecules, for preventive and curative therapeutic purposes and also as food additives or growth promoters [7]. A veterinary antibiotic that is used in compliance with label instruction does not result in 
residues at slaughter. possible reasons for such residues, however, include: failure to obey prescribed label instructions (extra-label use); failure to adhere to prescribed withdrawal times; administering too large an amount at a single injection site and giving animals access to spilled chemicals or medicated feed are some risk factors [10].

Disease Status: Biotransformation is the principal mechanism of elimination by the transformation of drugs into metabolites through a chemical reaction. Diseases can affect the pharmacokinetics of administered drugs which may increase the potential for persistence of residues [14]. This can happen when the disease affects an animal's digestive system or when the presence of disease allows the drug to accumulate in the infected tissues. [29]. An animal's disease status can affect the influence of the potential for antibiotic residues. This can happen either when the disease influences the metabolic system, or when the presence of infection and/or inflammation allows the drug to accumulate in affected tissues. The changes in liver function by fasciolosis result in a change in the processing of drugs through the liver. The renal disorder typically has a major effect on excretion drugs [25].

Extra-label drug use (ELU): Extra-label Drug Use (ELU) refers to the use of an approved drug in a manner that is not by the approved label directions. ELU occurs when a drug only approved for human use is used in animals, when a drug is approved for one species of animal is used in another when a drug is used to treat a condition for which it was not approved, or the use of drugs at levels over recommended dosages [19].

Improper withdrawal time: The withdrawal time (also known as the depletion or clearance period) is the time for the residue of toxicological concern to reach a safe concentration as defined by the tolerance [45]. Different antibiotics have their own withdrawal time, so if a breeder does not see their withdrawal time while they are used, it can lead to develop antibiotic residues in the edible tissue of animals [34]. Based on the drug product, dosage form, and route of administration it may vary from a few hours to days or weeks.

The drug withdrawl time is the interval from the time an animal is removed from medication until permitted time of slaughter for the production of safe foodstuff and fail to wait for the withdrawal period results in residue in the food of animal origin which is used for human consumption [46]. Some antibiotics are quickly excreted from the animal, others are not readily metabolized or excreted and so, their residues will persist in the animal tissues and hence enter the human food chain constituting health risks to the consumers [31].

Feed type and Age of animal: The quality of animal feed is important for the production of safe food for human consumption [24]. The elimination half-life of the antibiotic drug is shorter in unweaned calves than in adult cows, while the elimination half-life of apramycin is longer in calves than in adult cattle, possibly due to the immaturity of the drug clearance system. Diet can affect the bioavailability of drugs [39].

Toxicological and public health hazards of consuming beef with antibiotic residue

Human beings are the ultimate consumer of antibiotic residue in beef which causes significant health problems that might be toxicological, microbiological, or immunological [21]. Health hazards in humans that result from the consumption of beef with antibiotic residues include the transfer of antibiotic-resistant strain bacteria known to be foodborne pathogens [46] immunological effects, harmful effects on human intestinal microflora, and carcinogenicity [30].

Development of antibiotics resistance: Antimicrobial usage within the veterinary industry can result in the presence of antimicrobial residues in food of animal origin [56]. Animal feeds containing antibiotics have been reported to result in antimicrobial resistance, leading to failure of medical treatment both in animals and humans. Antibiotics resistant pathogens are one of the world's most pressing health problems because the number of bacteria resistant to antibiotics has increased in the last decade and many bacterial infections are becoming resistant to the most commonly prescribed treatment [58].

Indiscriminate use of veterinary antimicrobials in food animals plays a major role in the development of antimicrobial resistance (AMR) which has put the public health at risk [16]. Irrational use through free access to prescription drugs and their administration at sub-therapeutic concentrations for a long time favor the selection and spread of antimicrobial-resistant strains in animals, the environment, and humans [58]. The development and spread of antimicrobial resistance represent a serious threat to potential public health implications. The WHO has identified antibiotic resistance as one of the three greatest threats to human health [51]. The consumption of meat containing residues of antibiotics over a long period may lead to the emergence of resistant gut flora and pathogens in human beings. Antibiotic-resistant strains of enteric bacteria have been isolated more frequently from cattle given low feed concentrations of tetracyclines than from those fed drugfree rations [11].

Drug hypersensitivity reaction: Drug hypersensitivity is an immune-mediated response to a chemical agent (e.g. antibiotic drug) in a sensitized patient. Drug allergy is restricted to a reaction mediated by $\operatorname{IgE}$ and could be elicited following administration of antibiotic drugs or macromolecules such as protein, lipids, and carbohydrates [55]. Allergic reactions to antibiotic residue in the food of animals may include: anaphylaxis, serum sickness, cutaneous reaction, delayed hypersensitivity response to drugs appear to be more commonly associated with the antibiotics, especially of penicillin [38].

Penicillin residue as well as other -lactams antibiotics such as cephalosporin could cause allergies if a high level of residues persists in food products and is consumed by penicillin-allergic persons [22]. Such class of humans consuming meat products having penicillin residues is at risk of developing allergy which can manifest as a skin rash or even severe anaphylaxis. Studies have also shown that damages done to hepatic liver cells can be traced to an allergic response to macrolide antibiotics (e.g. erythromycin, clarithromycin) [54].

Carcinogenic effect: The term carcinogenic refers to any substance or an agent capable of altering the genetic makeup of an organism so that they multiply and become cancorous and while Carcinogenic effects refer to an effect produced by a drug having a carcinogenic or cancer-producing activity [57]. Antibiotics 
residues in food of animal origin can cause cancer if they are consumed regularly. The potential hazard of antimicrobial residues to cause cancer [23] was related to their collaboration or covalently binding to various intracellular components such as proteins, deoxyribonucleic acid (DNA), ribonucleic acid (RNA), glycogen, phospholipids, and glutathione [12].

Mutagenic effect: The term mutagen is used to describe physical or chemical agents that can cause a mutation in a DNA molecule thereby altering the genetic makeup of a cell or organism or damage the genetic component of a cell or organism [28]. There has been an increasing potential hazard to the human population by the production of genes mutations or chromosome aberrations. The antibiotic residues in beef cause a chronological effect on the human population by causing gene mutation or chromosome breakage which affects human inheritance [13].

Teratogenic effect: Congenital malformation of the fetus during pregnancy as a result of toxic metabolites of drugs or chemical agents has been reported. The teratogen applies to drug or chemical agents that alter the structural and functional integrity of the developing embryo/fetus during the critical phase of gestation [30]. Consequently, a congenital malformation, which affects the structural and functional integrity of the organism, was produced [28].

Disruption of Normal Intestinal Flora: Normal Intestinal Flora plays an important role in human physiology. The bacteria that usually live in the intestine acts as a barrier to prevent the incoming pathogen from being established and causing diseases [46]. Intestinal flora can control and prevent the colonization of potentially pathogenic microorganisms in the gastrointestinal tract [36]. Antibiotic residues in animal source foods are responsible for the modification of the intestinal flora [48].

\section{Detection of antibiotic residue in beef}

Screening Test: Screening of food products from the animal origin for the presence of antibiotic residues started long time ago. An efficient screening method needs to be low-cost and highthroughput, able to effectively identify potential non-compliant samples from a large set of negative samples. The advantage of those ways is that they have a large detection spectrum; they're easy to hold out and cheap and might be used for the screening of an oversized range of samples [35].

Biosensors: Biosensor is a device that integrates a biological element with a physiochemical transducer to produce an electronic signal proportional to a single analyte which is then conveyed to a detector. Different types of biosensors are developed in recent years as another approach to screen antibiotics in beef. In general, these sensors sometimes contain associate protein as a recognition component that interacts with the analyte [42]. The resulting biochemical signal is measured optically or regenerates into an associate sign that's additionally processed in applicable equipment. In general, these sensors are valid for control laboratories because they can detect multiple residues in one sample and can thus allow the analysis of a large number of residues and samples [4].

Biological methods: Biological screening methods were the earliest forms to have been developed, and their use is still widespread, as they are cost-effective and have a broad spectrum [50].
Biological methods are not selective and can cover several chemical classes of active antibiotics and detect cellular responses to the antibiotic residue (e.g. inhibition of bacterial growth). They do not allow the identification of individual antibiotics most antibiotic residue such as oxytetracycline, tetracycline, chlortetracycline, and doxycycline [33].

Biochemical methods: Biochemical methods may be a technique to detect molecular interactions (e.g. antigens, proteins) between antibiotics and antibodies or receptor proteins (e.g. Enzyme-Linked Immunosorbent Assay, ELISA) [54], chemical labeling of either the antibiotics or antibody/receptor permits the interaction to be monitored and measured. These ways have supported the interaction of antigen-antibody that is incredibly specific for selected residue and either selected for a family of antibiotics having connected molecular structures or ar typically antibiotics specific [20]. The most usual technique consists of the enzyme-linked-immunosorbent assay (ELISA) and therefore the detection system is typically supported enzyme-labeled reagents. There are different formats for matter quantification just like the double protein or sandwich ELISA tests and direct competitive ELISA tests [59].

Physicochemical methods: This technique is used to differentiate the chemical structure and molecular characteristics of antibiotics by separation of molecules (e.g. High Pressure Liquid Chromatography, HPLC) and therefore the detection of signals associated with molecular characteristics (e.g. UV, ) [54]. They will distinguish between similar molecular structures and permit the synchronal analysis of many antibiotics [3]. HPLC is a separative technique wherever the selection of the detection system is extremely vital for property and sensitivity. Some analytes need chemical modifications to render chemical group, fluorescent or UV-absorbing compounds [26].

Typical detections of multi-residues in meat samples ar comparatively easy and fast, requiring a preliminary clean-up through solid-phase extraction followed by filtration before injection into a reverse-phase HPLC with diode array detection. This procedure has been applied to beef for the detection of antibiotics like quinolones, sulphonamides, b-lactams and macrolides [33].

\section{The Extent of Veterinary Antibiotic Residue in Ethiopia}

In many African countries, including Ethiopia, antibiotics could also be used indiscriminately for the treatment of microbial diseases or they will be used as feed additives for cattle. The continued threat of antibiotic contamination is one in every of the most important challenges to public health that's faced by the human population worldwide. Such residues are spreading quickly, no matter geographical, economical, or legal variations between countries [53].

In Ethiopia, a study conducted in 2007 indicated the proportion of tetracycline levels in beef; the study targeted on the Addis Ababa, Debre Zeit, and town slaughterhouses. Out of the whole 384 samples analyzed for tetracycline residues, $71.3 \%$ had detectable antibiotic levels. Among the meat samples collected from the Addis Ababa, Debre Zeit, and Nazareth slaughterhouses, 93.8\%, $37.5 \%$, and $82.1 \%$ tested positive for oxytetracycline respectively. The mean levels of oxytetracycline in muscle from the three slaughterhouses were as follows: Addis Ababa, $108.34 \mu \mathrm{g} / \mathrm{kg}$; 
Nazareth, $64.85 \mu \mathrm{g} / \mathrm{kg}$; and Debre Zeit, $15.916 \mu \mathrm{g} / \mathrm{kg}$. Regarding kidney samples, oxytetracycline levels were found to be $99.02 \mu \mathrm{g} /$ $\mathrm{kg}$ in Addis Ababa, $109.35 \mu \mathrm{g} / \mathrm{kg}$ in Nazareth, and $112.53 \mu \mathrm{g} / \mathrm{kg}$ in Debre Zeit. About $48 \%$ of the edible tissues had oxytetracycline levels above the recommended maximum limits.

\section{Preventive and Control of antibiotic residue}

Preventive and Control of antibiotic residue in beef animals: Antibiotic residues are best avoided by implementing management practice and herd health program that keep animals healthy and producing efficiently; beef producers should carryout Proper drug administration and identification of treated animals [40]. The residue prevention strategy is based on preventing the entry of antibiotic residues in beef by proper administration of antimicrobials by veterinarians and apply herd health program that keep animals safe and healthy [42].

Avoid Prolonged exposure to subtherapeutic antibiotic doses leads to the proliferation of resistant bacterial strains [6].

The residue prevention strategy is by implementing management practice and herd health program that keeps animals healthy and producing efficiently; beef producers ought to carryout correct drug administration of and identification of treated animals [40]. Residue testing ought to be considered; the correct choice and interpretation of tests; the inherent limitation and potential misuse of residue testing. microbic inhibitions assays were the earliest ways used for the detection of antibiotic residues and that the area unit is still widely used [42].

Preventive and Control of antibiotic residue in humans: Rapid screening ways ought to be developed for detecting and segregating samples contains above MRL levels of antibiotics. Follow best hygiene practices throughout animal rearing and avoid unwanted use of antibiotics and victimization plant-derived antimicrobial substances and probiotics, could represent a promising option; vaccination against some microorganism diseases could also be of nice worth shortly [37]. Strict observation of antibiotic halt times ought to be made; the turning away of antibiotics lacking documented pharmacokinetic and pharmacodynamic properties should be thought of. Making awareness of correct drug use, and ways to avoid marketing adulterate products in the society, human capacity building for better diagnosis, control and preventation [35].

\section{Conclusion And Recommendations}

The extensive use of antibiotics in farm animals has the potential to generate residues in beef and poses a health hazard to the consumer. Human management, such as improper usage, including extra-label or illegal drug applications lead to the development of many troubles such as teratogenic and carcinogenic effects, allergic reactions and antibiotic resistance which can threaten human health due to the presence of antibiotic residues in food originated from animals. The side effect should be avoided by treating the causes of this problem and to start from veterinarian's and owner's awareness, controlling the withdrawal period and misuse of antibiotics.

Based above information the following recommendations are for- warded:

Scientific guidelines and precautions to minimize antibiotic residue will be strictly forwarded in the food of farm animals and discourage the advertisement of antibiotic as feed additives.

$>$ Animal diseases and infections should primarily be prevented by ensuring biosecurity, following good production, and good management practices.

> Animal for slaughter be accompanied with identification ID passport indicating previously history and drug usage

$>$ Knowledge and Public awareness should be created on the health significance of antibiotic residue.

$>$ Further research should be conducted into zoonotic importance, detection and potential prevention and control strategies.

\section{Acknowledgements}

We were like to express our gratitude to Ambo University, College of Agriculture and Veterinary Medicine and the Staff of School of Veterinary Medicine for inspiration and comprehensive moral support.

\section{Statement of Interest}

$>$ The authors declare that there is no conflict of interest on the publication of this manuscript.

\section{References}

[1]. Agmas B, Adugna M. Antimicrobial residue occurrence and its public health risk of beef meat in Debre Tabor and Bahir Dar, Northwest Ethiopia. Vet World. 2018 Jul;11(7):902-908. pubmed PMID: 30147257.

[2]. Alhendi AB, Homeida AA, Gaili ES. Drug residues in broiler chickens fed with antibiotics in ration. Veterinarski arhiv. 2000 Aug 20;70(4):199-206.

[3]. Araby E, Nada HG, Abou El-Nour SA, Hammad A. Detection of tetracycline and streptomycin in beef tissues using Charm II, isolation of relevant resistant bacteria and control their resistance by gamma radiation. BMC Microbiol. 2020 Jun 29;20(1):186. Pubmed PMID: 32600267.

[4]. Au HW, Tsang MW, So PK, Wong KY, Leung YC. Thermostable $\beta$-Lactamase Mutant with Its Active Site Conjugated with Fluorescein for Efficient $\beta$-Lactam Antibiotic Detection. ACS Omega. 2019 Nov 27;4(24):2049320502. Pubmed PMID: 31858033.

[5]. Awaisheh SS, Khalifeh MS, Rahahleh RJ, Al-Khaza'leh JM, Algroom RM. Sulfamethazine contamination level and exposure assessment in domestic and imported poultry meats in Jordan. Vet World. 2019 Dec;12(12):19921997. Pubmed PMID: 32095052.

[6]. Babapour A, Azami L, Fartashmehr J. Overview of antibiotic residues in beef and mutton in Ardebil, North West of Iran. World Appl Sci J. 2012;19(10):1417-22.

[7]. Berghiche A, Khenenou T, Labiad I. A Meta-Analysis on antibiotic residues in meat of broiler chickens in developing countries. Journal of World's Poultry Research. 2019;9(2):89-97.

[8]. Beyene T. Veterinary drug residues in food-animal products: its risk factors and potential effects on public health. J Vet Sci Technol. 2016;7(1):1-7.

[9]. Bou-Mitri C, Boutros PH, Makhlouf J, Jaoudeh MA, Gerges NE, Fares $\mathrm{JEH}$, et al. Exposure assessment of the consumers living in Mount Lebanon directorate to antibiotics through medication and red meat intake: A crosssectional study. Vet World. 2019 Sep;12(9):1395-1407. pubmed PMID: 31749573.

[10]. Caudell MA, Mair C, Subbiah M, Matthews L, Quinlan RJ, Quinlan MB, et al. Identification of risk factors associated with carriage of resistant Escherichia coli in three culturally diverse ethnic groups in Tanzania: a biological and socioeconomic analysis. Lancet Planet Health. 2018 Nov;2(11):e489e497. Pubmed PMID: 30396440.

[11]. Chang Q, Wang W, Regev-Yochay G, Lipsitch M, Hanage WP. Antibiotics in agriculture and the risk to human health: how worried should we be? Evol Appl. 2015 Mar;8(3):240-7. Pubmed PMID: 25861382.

[12]. Darko G, Borquaye LS, Acheampong A, Oppong K. Veterinary antibiotics in dairy products from Kumasi, Ghana. Cogent chemistry. 2017 Jan 


\section{$1 ; 3(1): 1343636$}

[13]. Al-Mashhadany DA. Detection of antibiotic residues among raw beef in Erbil City (Iraq) and impact of temperature on antibiotic remains. Ital J Food Saf. 2019 Mar 18;8(1):7897. Pubmed PMID: 31008087.

[14]. Falowo AB, Akimoladun OF. Veterinary drug residues in meat and meat products: occurrence, detection and implications. InVeterinary Medicine and Pharmaceuticals. 2019 Mar 10; 53.

[15]. Elbagory AM, Edris AM, Muhammad KM. Studies on residues of antibiotics and growth enhancer-hormone in imported and locally produced beef. Nutr. Food Technol. Open Access. 2007;3(2):1-5.

[16]. Ezenduka EV. Screening of antimicrobial residues in poultry meat in Enugu metropolis, Enugu State, South East Nigeria. Vet Ital. 2019 Jun 30;55(2):143-148. Pubmed PMID: 31274175

[17]. Ferdous MRA, Ahmed MR, Khan SH, Mukta MA, Anika TT, Hossain MT, et al. Effect of discriminate and indiscriminate use of oxytetracycline on residual status in broiler soft tissues. Vet World. 2020 Jan;13(1):61-67. Pubmed PMID: 32158152.

[18]. Mgonja F, Mosha R, Mabiki F, Choongo K. A simple and sensitive method for the detection of "Oxytetracycine" levels in ready-to-eat beef by liquid chromatography-mass spectrometry.

[19]. Gillian C. Avoiding drug carry over during feed processing and delivery. FDA Veterinarian Newsletter. 2003;6:30-45.

[20]. Granados-Chinchilla F, Rodríguez C. Tetracyclines in Food and Feedingstuffs: From Regulation to Analytical Methods, Bacterial Resistance, and Environmental and Health Implications. J Anal Methods Chem. 2017;2017:1315497. Pubmed PMID: 28168081.

[21]. Hind AE, Adil M, Samah A. Screening of antibiotic residues in poultry liver, kidney and muscle in Khartoum State, Sudan. studies. 2014;1:4.

[22]. Huang Y, Zhang Z, Hou T, Shi J, Huang W, Bai Z, et al. Antibiotic burden of school children from Tibetan, Hui, and Han groups in the QinghaiTibetan Plateau. PLoS One. 2020 Feb 24;15(2):e0229205. Pubmed PMID: 32092096.

[23]. Jabbar A. Microbiological evaluation of antibiotic residues in meat, milk and eggs. Journal of Microbiology, Biotechnology and Food Sciences. 2021 Jan 4;2021:2349-54

[24]. Khatun MM, Islam MA, Rahman MM. Current status of veterinary public health activities in Bangladesh and its future plans. BMC veterinary research. 2019 Dec;15(1):1-5.

[25]. Bayou K, Haile N. Review on antibiotic residues in food of animal origin: Economic and public health impacts. Applied Journal of Hygiene. 2017;6(1):01-8.

[26]. Kim J, Park H, Kang HS, Cho BH, Oh JH. Comparison of Sample Preparation and Determination of 60 Veterinary Drug Residues in Flatfish Using Liquid Chromatography-Tandem Mass Spectrometry. Molecules. 2020 Mar 7;25(5):1206. Pubmed PMID: 32156017

[27]. Kirchhelle C. Pharming animals: a global history of antibiotics in food production (1935-2017). Palgrave Communications. 2018 Aug 7;4(1):1-3.

[28]. Lee MH, Lee HJ, Ryu PD. Public health risks: Chemical and antibiotic residues-review. Asian-Australasian Journal of Animal Sciences. 2001;14(3):40213.

[29]. Lees P, Toutain PL. The role of pharmacokinetics in veterinary drug residues. Drug Test Anal. 2012 Aug;4 Suppl 1:34-9. Pubmed PMID: 22851359.

[30]. Fleming R. Nature vs. Nurture - Will the Species Survive? Scholarly Journal of Food and Nutrition. 2019; 2(1): 178-183.

[31]. Mangsi AS, Khaskheli MU, Soomro AH, Shah MG. Antibiotic residues detection in raw beef meat sold for human consumption in sindh, Pakistan. Int. J. Res. Appl. Nat. Soc. Sci. 2014;2(7):15-20

[32]. Mashak Z, Mojaddar Langroodi A, Mehdizadeh T, EbadiFathabad A, HoomanAsadi A. Detection of quinolones residues in beef and chicken meat in hypermarkets of Urmia, Iran using ELISA. Iran Agricultural Research. 2022 Jun 22;36(1):73-7.

[33]. Al-Mashhadany DA. Detection of antibiotic residues among raw beef in Erbil City (Iraq) and impact of temperature on antibiotic remains. Ital J Food Saf. 2019 Mar 18;8(1):7897. Pubmed PMID: 31008087

[34]. Mitchell MEV, Alders R, Unger F, Nguyen-Viet H, Le TTH, Toribio JA. The challenges of investigating antimicrobial resistance in Vietnam - what benefits does a One Health approach offer the animal and human health sectors? BMC Public Health. 2020 Feb 11;20(1):213. Pubmed PMID: 32046713.

[35]. Miranda CD, Godoy FA, Lee MR. Current Status of the Use of Antibiotics and the Antimicrobial Resistance in the Chilean Salmon Farms. Front Microbiol. 2018 Jun 18;9:1284. Pubmed PMID: 29967597.

[36]. Alla MB, Mohamed TE, Abdelgadir AE. Detection of Antibiotics Residues in Beef in Ghnawa Slauterhouse, Khartoum State, Sudan. Journal of Veterinary Medicine and Animal Production. 2013 Feb 10;2(1).

[37]. Moretti S, Dusi G, Giusepponi D, Pellicciotti S, Rossi R, Saluti G, et al. Screening and confirmatory method for multiclass determination of 62 antibiotics in meat. J Chromatogr A. 2016 Jan 15;1429:175-88. Pubmed
PMID: 26726937

[38]. EMA Committee for Medicinal Products for Veterinary Use (CVMP) and EFSA Panel on Biological Hazards (BIOHAZ), Murphy D, Ricci A, Auce Z, Beechinor JG, Bergendahl H, Breathnach R, et al. EMA and EFSA Joint Scientific Opinion on measures to reduce the need to use antimicrobial agents in animal husbandry in the European Union, and the resulting impacts on food safety (RONAFA). EFSA J. 2017 Jan 24;15(1):e04666. Pubmed PMID: 32625259 .

[39]. Mutua F, Sharma G, Grace D, Bandyopadhyay S, Shome B, Lindahl J. A review of animal health and drug use practices in India, and their possible link to antimicrobial resistance. Antimicrob Resist Infect Control. $2020 \mathrm{Ju}$ 8;9(1):103. Pubmed PMID: 32641109.

[40]. Omeiza GK, Ajayi IE, Ode OJ. Assessment of antimicrobial drug residues in beef in Abuja, the Federal Capital Territory, Nigeria. Vet Ital. 2012 JulSep;48(3):283-9. Pubmed PMID: 23038074.

[41]. Pena A, Lino CM, Alonso R, Barceló D. Determination of tetracycline antibiotic residues in edible swine tissues by liquid chromatography with spectrofluorometric detection and confirmation by mass spectrometry. J Agric Food Chem. 2007 Jun 27;55(13):4973-9. Pubmed PMID: 17550268.

[42]. Pikkemaat MG. Microbial screening methods for detection of antibiotic residues in slaughter animals. Anal Bioanal Chem. 2009 Oct;395(4):893905. Pubmed PMID: 19484227.

[43]. Abavelim DA. Determination of antibiotics residues in beef and mutton from some selected markets in Kumasi-Ghana (Doctoral dissertation).

[44]. Ramatla T, Ngoma L, Adetunji M, Mwanza M. Evaluation of Antibiotic Residues in Raw Meat Using Different Analytical Methods. Antibiotics (Basel). 2017 Dec 7;6(4):34. Pubmed PMID: 29215578.

[45]. Rana MS, Lee SY, Kang HJ, Hur SJ. Reducing Veterinary Drug Residues in Animal Products: A Review. Food Sci Anim Resour. 2019 Oct;39(5):687703. Pubmed PMID: 31728441.

[46]. Prajwal S, Vasudevan VN, Sathu T, Irshad A, Nayankumar SR, Pame K. Antibiotic residues in food animals: Causes and health effects. Pharma Innov J. 2017;6:1-4.

[47]. Sahu R, Saxena P. Antibiotics in chicken meat. Centre for Science and Environment. 2014 Jul.

[48]. SAMANDOULOUGOU S, BAGRE TS, SAVADOGO A, SCIPPO ML, TRAORE AS. Screening of antibiotics residues in beef consumed in Ouagadougou, Burkina Faso. African Journal of Food Science. 2015 Mar 30;9(6):367-71.

[49]. Sanz D, Razquin P, Condón S, Juan Esteban T, Herraiz B, Mata L. Incidence of antimicrobial residues in meat using a broad spectrum screening strategy.

[50]. Serrano MJ, Mitjana O, Bonastre C, Laborda A, Falceto MV, García-Gonzalo D, et al. Is Blood a Good Indicator for Detecting Antimicrobials in Meat? Evidence for the Development of In Vivo Surveillance Methods. Antibiotics (Basel). 2020 Apr 12;9(4):175. Pubmed PMID: 32290542.

[51]. Sirichoat A, Flórez AB, Vázquez L, Buppasiri P, Panya M, Lulitanond V, et al. Antibiotic Susceptibility Profiles of Lactic Acid Bacteria from the Human Vagina and Genetic Basis of Acquired Resistances. Int J Mol Sci. 2020 Apr 8;21(7):2594. Pubmed PMID: 32276519.

[52]. Teixeira A, Silva S, Guedes C, Rodrigues S. Sheep and Goat Meat Processed Products Quality: A Review. Foods. 2020 Jul 20;9(7):960. Pubmed PMID: 32698535.

[53]. Ture M, Fentie T, Regassa B. Veterinary Drug Residue: The Risk, Public Health Significance, and its Management. Journal of Dairy \& Veterinary Science. 2019; 13(2): 001-002.

[54]. Vishnuraj MR, Kandeepan G, Rao KH, Chand S, Kumbhar V. Occurrence, public health hazards and detection methods of antibiotic residues in foods of animal origin: A comprehensive review. Cogent Food \& Agriculture. 2016 Dec 31;2(1):1235458.

[55]. Ngom RR, Garabed RB, Rumbeiha WK, Foyet HS, Schrunk DE, Shao D, et al. Penicillin-G and oxytetracycline residues in beef sold for human consumption in Maroua, Cameroon. International Journal of Food Contamination. 2017 Dec;4(1):1-1.

[56]. Watkins HS, Kožárová I. Broad spectrum detection of antibiotic residues in poultry meat by a multi-plate assay. Folia Veterinaria. 2019 Sep 1;63(3):917

[57]. WHO. Evaluation of certain veterinary drug residue in food. Tech. Rep. Ser. 2014; 988: 7-32

[58]. WHO Guidelines on Use of Medically Important Antimicrobials in FoodProducing Animals. Geneva: World Health Organization; 2017. Pubmed PMID: 29578662

[59]. Yuan M, Xiong Z, Fang B, Guo Z, Guo D, Lai W, et al. Preparation of an Antidanofloxacin Monoclonal Antibody and Development of Immunoassays for Detecting Danofloxacin in Meat. ACS Omega. 2020 Jan 2;5(1):667673. Pubmed PMID: 31956816 